Research Article

\title{
Electro-Thermal and Semiconductivity Behaviour of Natural Sintered Complex Carbonate Ore for Thermo-Technological Applications
}

\author{
Loutfy H. Madkour \\ Chemistry Department, Faculty of Science and Arts, Baljarashi, Al-Baha University, P.O. Box 1988, Al-Baha, Saudi Arabia \\ Correspondence should be addressed to Loutfy H. Madkour; loutfy.madkour@yahoo.com
}

Received 9 September 2013; Revised 8 December 2013; Accepted 6 January 2014; Published 5 March 2014

Academic Editor: Miguel A. Huerta-Diaz

Copyright (c) 2014 Loutfy H. Madkour. This is an open access article distributed under the Creative Commons Attribution License, which permits unrestricted use, distribution, and reproduction in any medium, provided the original work is properly cited.

The polymetal $\left(\mathrm{Zn}, \mathrm{Pb}, \mathrm{Fe}, \mathrm{Ca}, \mathrm{Mg}, \mathrm{Cd}, \mathrm{Ba}, \mathrm{Ni}\right.$, $\mathrm{Ti}$, and $\mathrm{SiO}_{2}$ ) complex Umm-Gheig carbonate ore is subjected to sintering treatment at $573,773,973$ and $1273 \mathrm{~K}$ respectively for four hours. Chemical, spectral, X-ray and differential thermal analyses are applied for the native ore as well as for the samples preheated and sintered. The current versus applied DC voltage $(I--V)$ characteristics, bulk density $\left(D_{\mathrm{b}}\right)$, percent shrinkage $(\% S)$, activation energy $\left(E_{\mathrm{a}}\right)$ and energy gap $\left(E_{\mathrm{g}}\right)$ are established for the sintered ore. The electrical conductivity $(\sigma)$, thermal conductivity $(K)$ and thermoelectric power coefficient $(\alpha)$ have been investigated as a function of applied temperature for the sintered ore materials. The electrical conduction is mainly achieved by free electrons near or in conduction band or n-type. As the sintering temperature $\left(T_{\mathrm{s}}\right)$ increases the conduction of the ore is also increased due to the recombination process taking place between the electrons and holes. Electrons hopping between $\mathrm{Fe}^{2+}$ and $\mathrm{Fe}^{3+}$ are the main charge carriers. The formation of $\mathrm{Fe}_{3} \mathrm{O}_{4}$ at high sintering temperature acts as an active mineralizer, thus inducing an increased degree of crystallinity and a more ordered crystal structure is produced.

\section{Introduction}

The polymetal deposits of the Red Sea ore belt (a zone extending NW-SE for a distance of $130 \mathrm{~km}$ ) represent a complex morphogenetic type of mineralization [1]. The chief minerals are hydrozincite, zinc blende, smithsonite, and cerussite, while silica and carbonates constitute the bulk of the gangue. The investigated sample contains $30.7 \% \mathrm{Zn}, 7.99 \%$ $\mathrm{Pb}, 5.05 \% \mathrm{Fe}$, and $6.58 \% \mathrm{SiO}_{2}$. The minerals present in the complex ore are often so closely intergrown that either it is difficult to obtain suitable high-grade concentrates at high recoveries [2] by physical methods, or the recovery of metals from the respective concentrates is poor. Madkour and others [3-8] investigated experimentally the thermochemistry of the complex ores roasting, giving some theoretical thermodynamic calculations, for the recovery of metal value. It is possible to control the calcine composition by controlling the temperature and air-solid, an important step for understanding the properties and conduction mechanism of $\mathrm{ZnO}$ [911]. The solid state sintering represents a classical method for obtaining of materials with wide application possibilities, as microwave materials [12], ferrite materials [13], and others. In this sense, the aim of the present work is to investigate the electrical and thermal properties of the natural polymetal complex ore with a series of sintering temperatures: 573,773 , 973 , and $1273 \mathrm{~K}$, respectively, as well as to directly examine the semiconductivity behaviour of the material, obtained by solid state sintering that may have thermotechnological applications.

\section{Materials and Methods}

2.1. Sampling. Mineralized horizon ore $(500 \mathrm{~kg})$ was crushed to $100 \%$ minus $1.0 \mathrm{~mm}$. The ore samples are finally mixed in an agate mortar to ensure homogeneous distribution. Discs of $1.1 \mathrm{~cm}$ diameter and $0.15 \mathrm{~cm}$ thickness were pressed at about $500 \mathrm{~kg} / \mathrm{cm}^{2}$ in a steel die using hydraulic press. The pressed discs were then sintered at $573,773,973$, and $1273 \mathrm{~K}$, respectively, for four hours under atmospheric pressure. The discs 


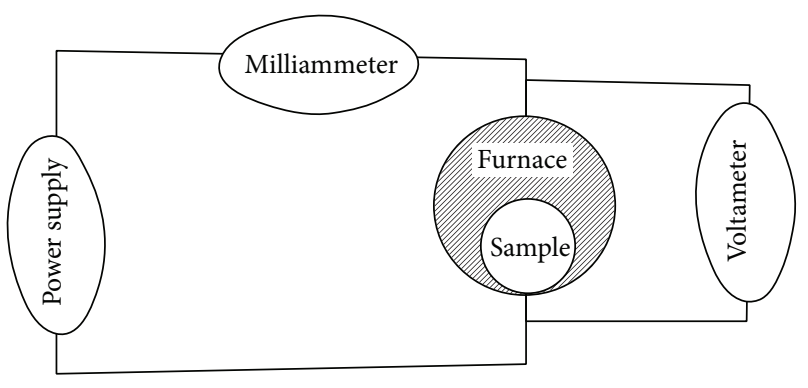

Figure 1: Essential electric circuit.

were polished and coated on both flat surfaces with graphite paste for electrical measurements.

2.2. Chemical Analysis. Analysis [14] of the ore sample was carried out at the Egyptian Geological Survey and Mining Authority.

2.3. Thermal Analysis. Analysis for the native ore sample was carried out by means of a MOM derivatograph with $\alpha-\mathrm{Al}_{2} \mathrm{O}_{3}$ as reference. The powdered ore sample was heated at the rate of $10^{\circ} \mathrm{C} / \mathrm{min}$ up to $1000^{\circ} \mathrm{C}$ (constant sensitivities: DTA, $1 / 10$, TG; 200 and DTG, 1/15). Differential thermal analysis (DTA) of the investigated sintered ore sample was carried out using a Schimadzu XD-3-thermal analyzer.

2.4. X-Ray Analysis. The X-ray powder diffraction pattern was obtained using $\mathrm{Cuk}_{\alpha}$ radiation and a nickel filter. A Phillips X-ray PW 1729, diffractometer has been used in the range $2 \theta=12-80$.

2.5. Infrared Spectra. The infrared spectra ( $\mathrm{KBr}$ discs) were recorded on a Perkin-Elmer 1430 Ratio Recording spectrophotometer and a Perkin-Elmer 683 spectrophotometer.

2.6. Electrical Measurements. The $I-V$ characteristic measurements were obtained with a digital multimeter type KIETHLEY $130 \mathrm{~A}$, as a voltmeter and as milliamperemeter. The digital thermometer was used to measure the temperature with an accuracy of $\pm 0.1^{\circ} \mathrm{C}$. The essential electric circuit is shown in Figure 1. The apparatus used for the thermal measurements [15] is shown in Figure 2. It consists of a sample holder held on three iron rods. The sample holder consists of a stainless steel bar which is fixed in the central axis of tubular stainless steel furnace working with a heater. The central steel bar, copper leads thermocouple wires, and heater connections are insulated from the holder base plate by a ceramic disc. Various wires and thermocouples are connected to the outside by means of copper leads through Teflon tubes. The sample $S$ is slightly pressed by means of a small load placed on its top just to maintain good contact between the sample surfaces and the two copper electrodes. A metal jacket cooled with water through a copper coil placed around it rests on an annular vacuum rubber ring fixed to the base plate. The degree of vacuum was $10^{-3} \mathrm{~mm} \mathrm{Hg}$, and the heat leak due to convection was practically negligible. The thermal

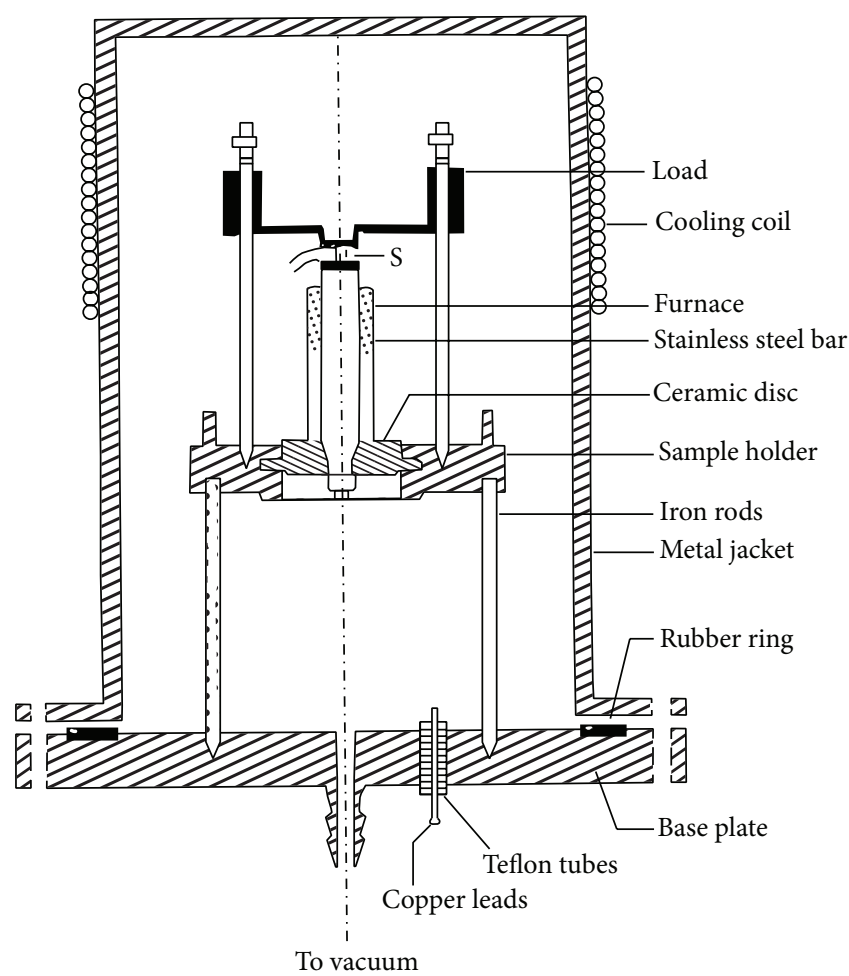

FIGURE 2: Cross section of the apparatus used for thermal measurements.

conductivity $(K)$ was measured at different temperatures (30$240^{\circ} \mathrm{C}$ ). This was achieved by controlling the furnace heater to maintain constant temperature at the lower surface of the sample and then the temperature gradient was measured.

\section{Results and Discussion}

3.1. Chemical Composition and Analysis. The investigated Umm-Gheig native ore sample was found to contain $59.76 \%$ $\mathrm{ZnCO}_{3}, 6.02 \% \mathrm{PbCO}_{3}, 4.86 \% \mathrm{PbSO}_{4}, 5.05 \% \mathrm{Fe}, 4.84 \% \mathrm{CaO}$, $6.58 \% \mathrm{SiO}_{2}$, and $2.58 \% \mathrm{MgO}$ as given in Table 1 . Thus, the natural ore is considered as zinc concentrate. Its constituents of $\mathrm{FeO}$ and $\mathrm{Fe}_{2} \mathrm{O}_{3}$ are relatively high.

Furthermore, the chemical analysis made on the sintered ore sample (after sintering at $1273 \mathrm{~K}$ for $4 \mathrm{hrs}$.) indicates an increase of $\mathrm{Fe}_{3} \mathrm{O}_{4}$ content at the expense of both originally present $\mathrm{FeO}$ and $\mathrm{Fe}_{2} \mathrm{O}_{3}$ content.

3.2. Thermal Analysis. Figure 3(a) displays the differential thermal analysis (DTA), thermogravimetry (TG), and derivative thermogravimetry (DTG) of the native ore sample. The arrangement of minerals $[16,17]$ according to their abundance is as follows: hydrozincite $\left[\mathrm{Zn}_{5}\left(\mathrm{CO}_{3}\right)_{2}(\mathrm{OH})_{6}\right]$; zinc blende $(\mathrm{ZnS})$; smithsonite $\left(\mathrm{ZnCO}_{3}\right)$, and cerussite $\left(\mathrm{PbCO}_{3}\right)$. The total loss on ignition in weight percent at $1100^{\circ} \mathrm{C}$ is $28.22 \%$. It can be seen that the native ore sample displays two endothermic peaks at $280^{\circ} \mathrm{C}$ and $370^{\circ} \mathrm{C}$, respectively. This is assigned to loss of humidity water content or physically combined water. Further temperature rise displays a whole 
TABLE 1: Chemical and spectral analysis of native Umm-Gheig natural complex polymetal ore.

\begin{tabular}{lccccc}
\hline Compound & Content (\%) & Compound & Content (\%) & Element & Content $\left(\right.$ parts $\left.\times 10^{-6}\right)$ \\
\hline $\mathrm{SiO}_{2}$ & 6.58 & $\mathrm{Zn}$ & 30.70 & $\mathrm{Cd}$ & 800 \\
$\mathrm{Al}_{2} \mathrm{O}_{3}$ & 0.83 & $\mathrm{~Pb}$ & 7.99 & $\mathrm{Ti}$ & 0.06 \\
$\mathrm{Fe}$ & 5.05 & $\mathrm{PbSO}_{4}$ & 4.86 & $\mathrm{Ba}$ & 400 \\
$\mathrm{MgO}$ & 2.58 & $\mathrm{PbCO}_{3}$ & 6.02 & $\mathrm{Ni}$ & 40 \\
$\mathrm{CaO}$ & 4.84 & $\mathrm{ZnCO}_{3}$ & 59.76 & $\mathrm{Co}$ & - \\
$\mathrm{SO}_{4}{ }^{2-}$ & 1.28 & Moisture & 0.97 & $\mathrm{Ag}$ & - \\
L.O.I. $^{*}$ & 28.22 & & & $\mathrm{Au}$ & - \\
\hline
\end{tabular}

${ }^{*}$ Loss on ignition in weight percent at $1100^{\circ} \mathrm{C}$.

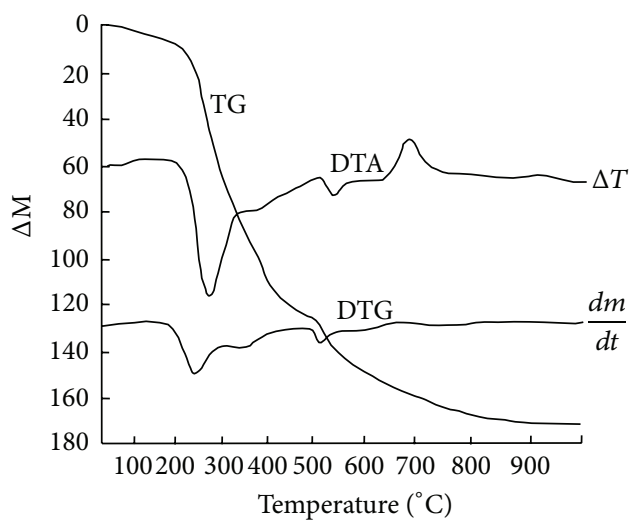

(a)

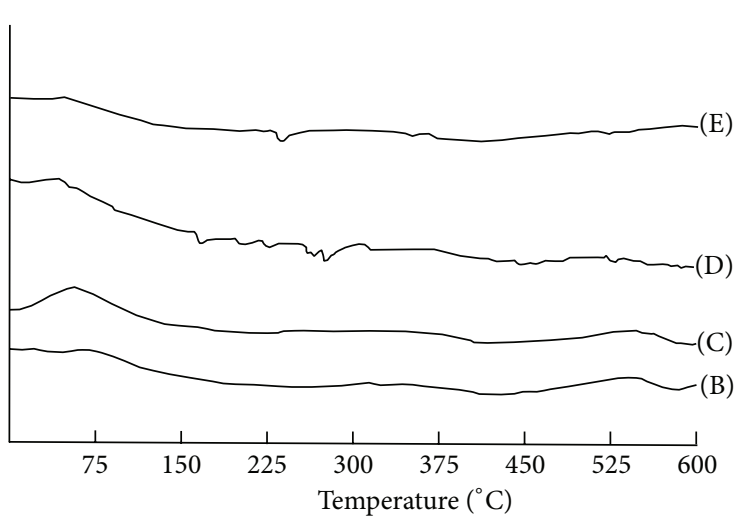

(b)

Figure 3: Thermal analysis of (a) the native ore sample and (b) sintered ore samples for 4 hrs at $573 \mathrm{~K}$ (B), $773 \mathrm{~K}$ (C), $973 \mathrm{~K}$ (D), and $1273 \mathrm{~K}$ (E).

intense broad exothermic hump covering the temperature range $400-550^{\circ} \mathrm{C}$ peaking at $500^{\circ} \mathrm{C}$ for the strongest one. This is due to collective phase changes [16] corresponding to the following reactions:

$$
\begin{gathered}
\mathrm{Fe}_{2} \mathrm{O}_{3} \stackrel{400^{\circ} \mathrm{C}}{\longrightarrow} \mathrm{Fe}_{3} \mathrm{O}_{4} \text { (magnetite) } \\
\mathrm{FeO} \stackrel{450^{\circ} \mathrm{C}}{\longrightarrow} \mathrm{Fe}_{2} \mathrm{O}_{3} \text { (hematite) } \\
\mathrm{Fe}_{2} \mathrm{O}_{3} \stackrel{500^{\circ} \mathrm{C}}{\longrightarrow} \mathrm{Fe}_{3} \mathrm{O}_{4} \text { (magnetite) }
\end{gathered}
$$

respectively. It is of importance to note that the native $\mathrm{Fe}_{2} \mathrm{O}_{3}$ (hematite) present and the formed $\mathrm{Fe}_{3} \mathrm{O}_{4}$ (magnetite) may act as catalyst, for the subsequent oxidation and oxygen uptake of $\mathrm{FeO}$ giving $\mathrm{Fe}_{2} \mathrm{O}_{3}$ and later on for the formation of $\mathrm{Fe}_{3} \mathrm{O}_{4}$ as a final product. Besides, it acts as an active mineralizer, thus inducing an increased degree of crystallinity [18] which often appears after the applied sintering treatment at 573, 773, 973, and $1273 \mathrm{~K}$, respectively.

The broad exothermic peak covering the temperature range $630-750^{\circ} \mathrm{C}$ peaking at $690^{\circ} \mathrm{C}$ for the strongest one corresponds to the decomposition of the original present metal carbonates and sulphates into the corresponding oxides.

Differential thermal analysis for the ore samples preheated and sintered at temperatures $573,773,973$, and $1273 \mathrm{~K}$, respectively, for hours is shown in Figure 3(b). DTA for the sintered ore indicates oxidation of various metal carbonates and sulphates present in the native ore into corresponding metal oxides.

3.3. X-Ray Analysis. X-ray diffraction studies ensured the chemical composition of the native Umm-Gheig natural ore and samples preheated and sintered at 573-1273 K, respectively, as shown in Figure 4. The X-ray diffraction pattern of raw material sample (Figure $4(\mathrm{~A})$ ) displays the essential characteristic peaks for $\mathrm{ZnCO}_{3}(2 \theta=33.70,25.10,51.25,37.80$, 46.40, 41.60, and 61.40), $\mathrm{PbCO}_{3}(2 \theta=25.80,36.40,43.80$, 29.00, 49.20, 36.40, and 47.30), $\mathrm{PbSO}_{4}(2 \theta=29.50,26.80$, $44.50,27.40$, and 22.10$)$, and $\left[\mathrm{Zn}_{5}\left(\mathrm{CO}_{3}\right)_{2}(\mathrm{OH})_{6}\right](2 \theta=36.40$, $33.70,29.00,25.10,30.70$, and 16.80). X-ray powder diffraction data shows that galena is mainly converted to cerussite.

After the sintering treatment at 573, 773, 973, and $1273 \mathrm{~K}$ for four hours, respectively, the X-ray diffraction pattern of sintered ore samples (Figures $4(B)-4(E)$ ) displays the characteristic deflection peaks for different metal oxides formed as follows:

$\mathrm{ZnO}(2 \theta=36.10,31.70$, and 33.80): $\mathrm{PbO}(2 \theta=29.10,31.60$, $32.15,48.70$, and 45.60): $\mathrm{PbO}_{2}(2 \theta=28.15,49.55$, and 22.80): $\mathrm{Pb}_{2} \mathrm{O}_{3}\left(2 \theta=29.50,29.60\right.$, and 27.40): $\mathrm{Pb}_{3} \mathrm{O}_{4}(2 \theta=26.20,31.60$, and 32.15): $\mathrm{FeO}\left(2 \theta=41.95,36.20\right.$, and 61.00): $\mathrm{Fe}_{2} \mathrm{O}_{3}(2 \theta=$ $33.50,35.60$, and 54.20): $\mathrm{Fe}_{3} \mathrm{O}_{4}(2 \theta=35.60,62.40$, and 29.60).

The X-ray diffraction studies of sintered ore samples at higher sintering temperatures (Figure 4) ensured a spinel phase formation $\left(x \mathrm{Fe}_{2} \mathrm{O}_{4}\right)$, where $x=\mathrm{Zn}$ or $\mathrm{Pb}$. The essential 


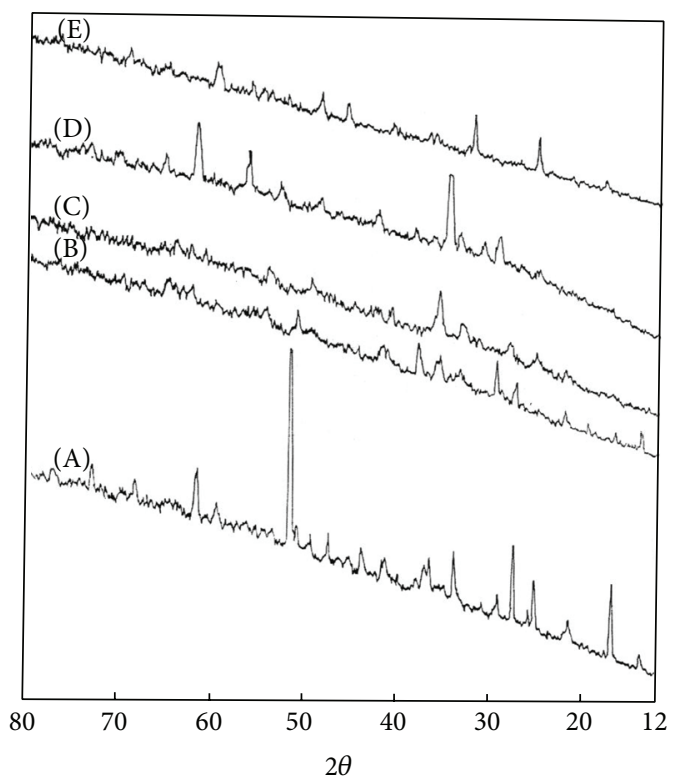

FIgURE 4: X-ray diffraction pattern for the native ore sample (A) and sintered ore samples for $4 \mathrm{hrs}$ at $573 \mathrm{~K}$ (B), $773 \mathrm{~K}(\mathrm{C}), 973 \mathrm{~K}$ (D), and $1273 \mathrm{~K}(\mathrm{E})$.

characteristic peaks for spinel $\mathrm{ZnFe}_{2} \mathrm{O}_{4}$ and $\mathrm{PbFe}_{2} \mathrm{O}_{4}$ are $2 \theta=35.00,29.60,62.05$, and 56.60 and $2 \theta=32.40,46.00$, $56.80,74.40$, and 67.40 , respectively. Furthermore, there is no indication for the appearance of reflection peaks characteristics of the carbonate mineral or sulphate composition which was originally present in the native ore before thesintering processes at $573-1273 \mathrm{~K}$. This is due to the thermal decomposition of the main minerals present, into the corresponding metal oxides.

3.4. Infrared Spectra. The IR frequencies of the native UmmGheig ore sample (A) and the sintered ore samples (B-E) along with their assignments are given in Figure 5. The bands at $1677-1632 \mathrm{~cm}^{-1}$ are assigned to the $\nu \mathrm{C}=\mathrm{O}$ groups. Metallic carbonyls absorb in the $1984 \mathrm{~cm}^{-1}$ region [19]. Silicates give absorption bands in the $1168-915 \mathrm{~cm}^{-1}$ range. Appearance of new bands in the frequency region at $332-328 \mathrm{~cm}^{-1}$ (Figures $5(\mathrm{~B})-5(\mathrm{D}))$ is due to stretching vibration bands of metal oxide ( $\mathrm{M}-\mathrm{O}$ ) bonds, where $\mathrm{M}=\mathrm{Zn}, \mathrm{Pb}$, or Fe. The existence of water molecules within the coordination sphere of the hydrated ore samples is supported by the presence of absorption bands in the regions $3889-3422 \mathrm{~cm}^{-1}$ and $1116-1073 \mathrm{~cm}^{-1}$ in the spectra of the ore due to $(\mathrm{OH})$ stretching, $\mathrm{HOH}$ deformation, and $\mathrm{H}_{2} \mathrm{O}$ rocking [20].

3.5. Effect of Sintering Temperature on the Bulk Density $\left(D_{b}\right)$ and Shrinkage $(\% S)$. The measured diameter of the sintered ore discs is decreased as the sintering temperature increases; therefore the percent shrinkage $(\% S)$ of the sintered ore samples is consequently increased with increasing the sintering temperature (Figure 6$)$. The bulk density $\left(D_{\mathrm{b}}\right)$ is also measured for the different sintered ore discs and the data

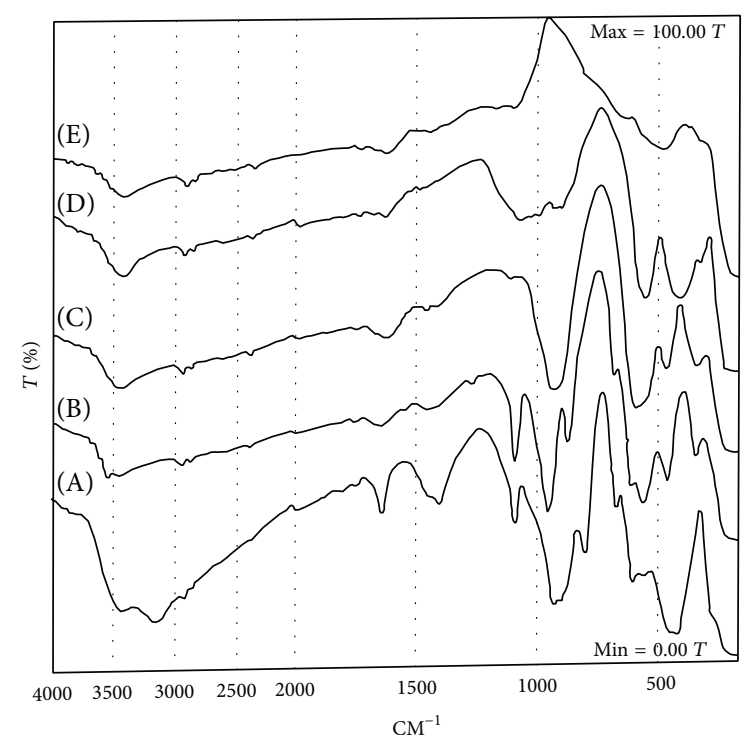

FIGURE 5: Infrared spectra of the native ore sample (A) and sintered ore samples for $4 \mathrm{hrs}$ at $573 \mathrm{~K}$ (B), $773 \mathrm{~K}$ (C), $973 \mathrm{~K}$ (D), and $1273 \mathrm{~K}$ (E).

is plotted as a function of the sintering temperature $\left(T_{\mathrm{s}}\right)$ as represented in Figure 6. The results show that the bulk density as well as the percentage shrinkage increased gradually with increasing sintering temperature in the temperature range $573-1273 \mathrm{~K}$. This behaviour may be due to the more diffusive [21] process occurring at high sintering temperature, leading to porosity reduction. As a result of this contraction, the crystal structure becomes compacted and rigid at high sintering temperature. The observed small values of $\left(D_{\mathrm{b}}\right)$ and $(\% S)$ at lower sintering temperatures can be attributed to the limited rearrangement of the crystal lattice structure through the movement of grain boundaries [22].

3.6. Temperature Dependence of Electrical Properties. The $I-V$ characteristics have been measured on the sintered ore samples at the different sintering temperatures studied, ranging from 573 to $1273 \mathrm{~K}$, as shown in Figure 7. From this figure we can see that the $I$ versus $V$ plots are, on the whole, straight lines at all different sintering temperatures. The plot is converted also to $\log I$ versus $\log V$, as represented in Figure 8 . It is evident from this figure that at the applied DC voltages an ohmic relationship $(\alpha=1)$ is obtained for all sintered samples with the exception of the ore sample sintered at $773 \mathrm{~K}$. This behaviour is called the current ohmic range. But for the case of the sintered sample at $773 \mathrm{~K}$, the nonohmic relation, $I \equiv$ $V^{\alpha}$, holds well. The parameter $\alpha$ which essentially defines the nonohmic nature of the material equals 1.52 and 1.95 for the lower and upper branches lines, respectively. The nonohmic region $(\alpha>1)$ in the $I-V$ curves arises due to the space-charge effects and is termed as the space-chargelimited current (SCLC) region. These observations show that the $I-V$ characteristics provide the best understanding of the conduction mechanism in the ore samples. The tested ore material may be considered to be composed of layers 


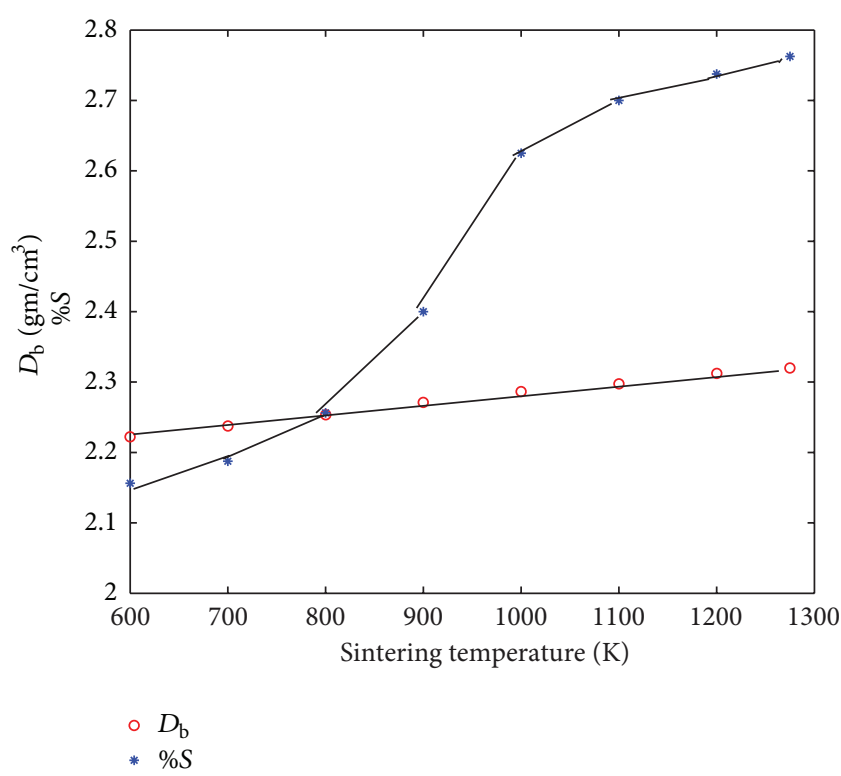

Figure 6: Effect of sintering temperature $\left(T_{\mathrm{s}}\right)$ on the bulk density $\left(D_{\mathrm{b}}\right)$ and shrinkage $(\% S)$ of the ore samples.

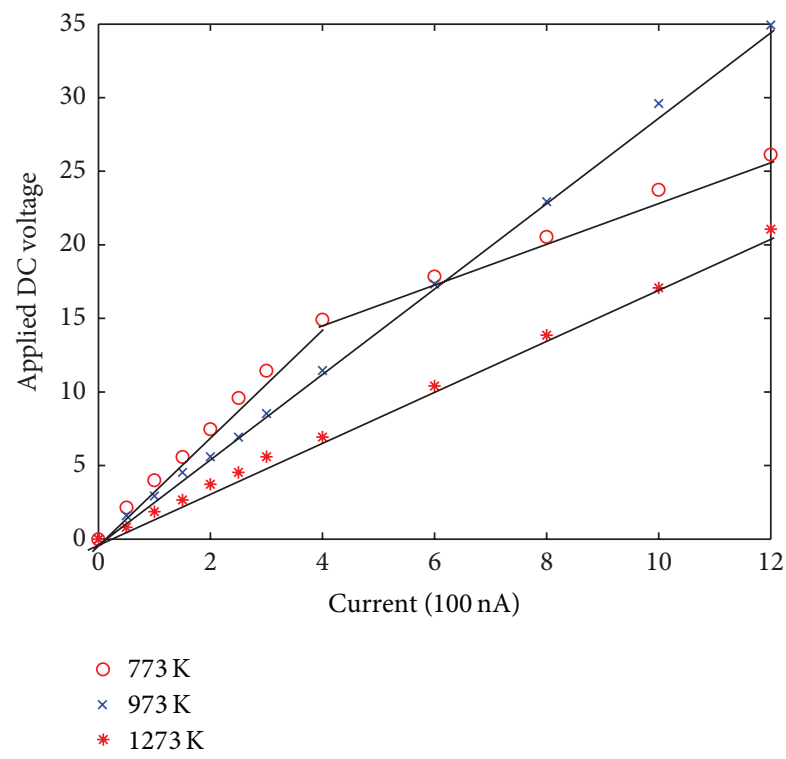

FIGURE 7: DC current voltage characteristic of sintered ore samples.

with different conductivities and thicknesses in series with each other. The well-conducting grains, having thickness $d_{1}$, conductivity $\sigma_{1}$, and permittivity $\varepsilon_{1}$, are separated by a thin layer of poorly conducting grain boundaries (GB) having a thickness $d_{2}$, a conductivity $\sigma_{2}$, and a permittivity $\varepsilon_{2}$. It is reasonable to assume that $\sigma_{1} \gg \sigma_{2}$. If $V_{1}$ and $V_{2}$ are the DC voltage drops across the grain and the GB, respectively, then $V=V_{1}+V_{2}$ is the externally applied DC voltage. The voltage drop will take place mainly across the grain boundary (i.e., $V \cong V_{2}$ ). If the current $\left(i_{\Omega_{1}}\right)$ through the grain is only ohmic and the current through the GB is ohmic $\left(i_{\Omega_{2}}\right)$ as well as space-charge-limited $\left(i_{\text {scl }}\right)$, the total current $(I)$ is then

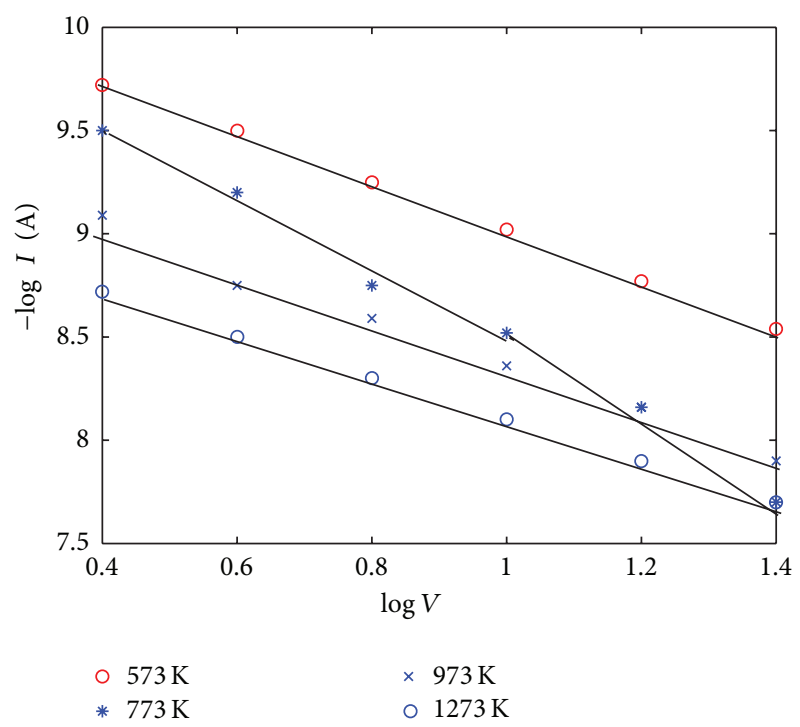

FIGURE 8: Logarithmic current voltage characteristic of sintered ore samples.

$I=i_{\Omega_{1}}+i_{\Omega_{2}}+i_{\text {scl }}$. The total current in the ore solid can be approximated as $i_{\Omega_{2}} \ll i_{\text {scl }} \cong I$. Thus, the $I-V$ characteristic in the nonohmic region is given by $i_{\mathrm{scl}} \equiv V_{2^{\alpha}}$. The space-chargelimited current is determined mainly by the number of free charge carriers available in the grain-boundary layers. At the applied DC voltages on the ore samples, that is, before the nonohmic region (at $773 \mathrm{~K}$ sintered ore sample), the current is purely ohmic $(\alpha=1)$. In this region the total current through the ore solid is $i_{\text {scl }} \ll i_{\Omega_{2}} \cong i$, and hence an ohmic relation holds. According to this theory [23], the $I-V$ curves consist of three parts:

(i) low-current ohmic range, for the sintered ore at $1273 \mathrm{~K}(\alpha=0.93)$,

(ii) SCLC range or the nonohmic range, for the sintered ore at $773 \mathrm{~K}\left(\alpha_{1}=1.52, \alpha_{u}=1.95\right)$, where $\alpha_{1}$ and $\alpha_{u}$ represent the values of $\alpha$ at lower and upper line inflection (Figure 7), respectively.

(iii) high-current ohmic range for the sintered ore at $573 \mathrm{~K}$ $(\alpha=1)$.

The broken line of $I-V$ characteristic for the tested sintered ore sample at $773 \mathrm{~K}$ shows that the critical voltage $\left(V_{c}\right)$ at which the line is broken equals 15 volts. The dependence of the electrical resistivity of the sintered ore samples on the applied sintering temperature is given in Table 2 . The obtained data indicates that the resistivity of the sintered ore samples decreases as the sintering temperature increases for the samples. Electrical conductivity versus temperature characteristics $(\ln \sigma-1 / T)$ of all the investigated samples were measured and represented in Figure 9. From the typical $\log \sigma$ versus $1 / T$ characteristics, as shown in Figure 9, it is seen that the sintered ore samples had a good semiconductivity 
TABLE 2: The electrical resistivity $(\rho)$ as a function of sintering temperature.

\begin{tabular}{lc}
\hline Sintering temperature $(\mathrm{K})$ & Resistivity $\left(\rho \times 10^{7} \Omega \cdot \mathrm{cm}\right)$ \\
\hline 573 & 73.84 \\
773 & $21.10\left(\right.$ before $\left.V_{\mathrm{c}}\right)$ and $8.43\left(\right.$ after $\left.V_{\mathrm{c}}\right)$ \\
973 & 11.75 \\
1273 & 11.09 \\
\hline
\end{tabular}

behaviour with increasing applied temperature, from 430$550 \mathrm{~K}$ according to a Boltzmann distribution [24]:

$$
\sigma=\sigma_{\mathrm{o}}, \quad \frac{\mathrm{e}^{-E_{\mathrm{a}}}}{k T} .
$$

The parameter $\sigma_{o}$, which is given by the intercept of the line at $1 / T=0$, is called the preexponential factor or the frequency factor, $k$ is the Boltzmann constant, and $T$ is the absolute temperature. However, it is worth anticipating the interpretation of the activation energy $\left(E_{\mathrm{a}}\right)$ for the electric conduction in $\mathrm{eV}$, which is achieved by rewriting the above equation as

$$
\log \sigma=\log \sigma_{\mathrm{o}}-\frac{E_{\mathrm{a}}}{k} \cdot T .
$$

There we shall see that the activation energy $\left(E_{\mathrm{a}}\right)$ represents the minimum energy necessary for a molecule to have in the sample to react. $E_{\mathrm{a}}$ is calculated from the slope of the straight line of this plot (Figure 9). The values of activation energy $\left(E_{\mathrm{a}}\right)$ are plotted as a function of the sintering temperature $\left(T_{s}\right)$, as shown in Figure 10. The experimental results in Figures 9 and 10 indicate that the electrical conductivity increases and, consequently, the activation energies are decreased with increasing sintering temperature. The obtained data of either electrical conductivity (Figure 9) or activation energy (Figure 10) are in good agreement with those obtained from previous studies of the resistivity values, as given in Table 2. Also, the results obtained are in good agreement with other works [25] and can be explained on the basis that the propagation of lattice imperfection decreases while a more ordered crystal structure is produced.

Thus, all the investigated sintered ore samples have semiconductivity properties. Generally, in a semiconductor material the outer electrons or valence electrons are normally stable, that is, bound to their atoms and are not free to move. But when heat is applied or an impurity (a doping element) that serves to raise energy is incorporated, the application of a voltage will cause displacement of valence electrons in the material, that is, turn them into charge carriers. So, an electric current in a sintered ore semiconductor may be induced and varied over a wide range of sintering temperature only under the action of an external influence, such as heat and doping. The higher the temperature, the greater the number of free electrons and the higher the conductive current in the semiconductor. Thus, electrical conduction [26] in all semiconductors is mainly by free electrons near or in conduction band ( $n$-type). Since the electrons that participate in conduction are the semiconductor's own electrons, its

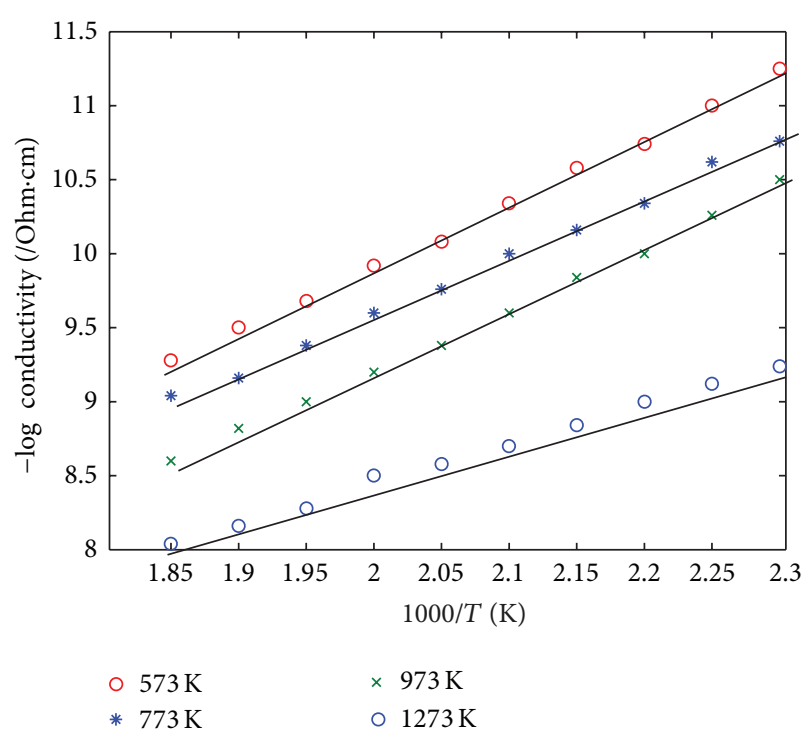

FIGURE 9: Temperature dependence of electrical conductivity $(\sigma)$ for sintered ore samples.

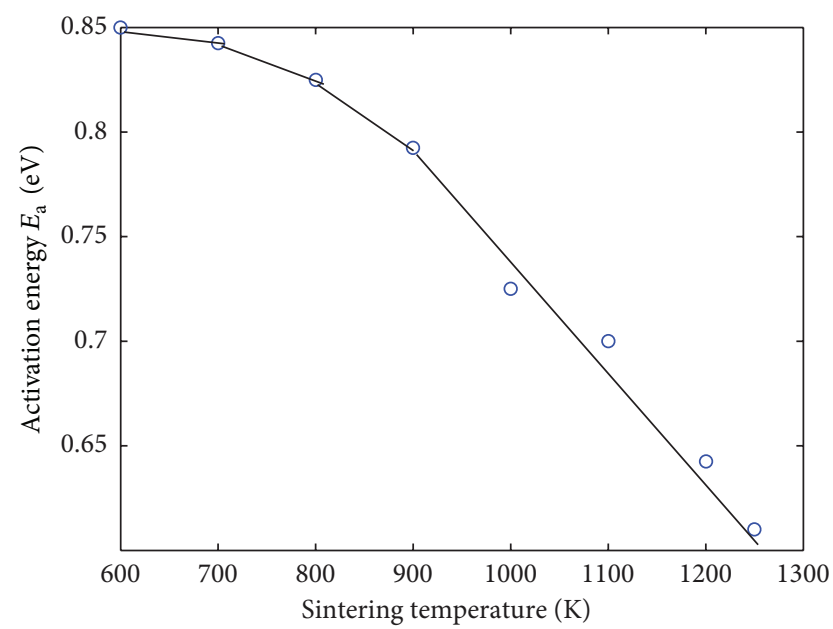

$\circ E_{\mathrm{a}}(\mathrm{eV})$

FIGURE 10: Effect of sintering temperature on the activation energy $\left(E_{\mathrm{a}}\right)$ for electrical conductivity of the ore samples.

conduction is called intrinsic. The atoms that lost their electrons turn into positive-charge ions bound and unable to move. The vacancy left by the electron in the outer ring of the atom is called a hole. An electron set free from the neighboring atom may fill the vacancy by moving to the hole and leaving instead a hole in its atom thereby turning it into a positively charged ion.

The application of an electric current to a semiconductor will cause electrons to move from atom to atom in one direction and leave holes in the opposite direction. The hole is generally regarded as a positive particle equal in charge to the electron. The seeming movement of holes in the direction opposite to that of electrons is called hole current. The electric conduction in the semiconductor, conditioned 
by this current, hole or p-type conduction. The movement of electrons in one direction and of holes in the opposite direction determines the intrinsic electrical conduction in a semiconductor because the charge carriers (electrons and holes) belong to the semiconductor's own atoms. In this case, the conduction current $I$ consists of the electron $I_{\mathrm{e}}$ and hole $I_{\mathrm{h}}$ current components, that is, $I=I_{\mathrm{e}}+I_{\mathrm{h}}$.

With intrinsic conduction, concentration of electrons $\left(N_{\mathrm{e}}\right)$ and of holes $\left(N_{\mathrm{h}}\right)$ is equal. However, $I_{\mathrm{e}}>I_{\mathrm{h}}$ because the mobility of electrons is higher than that of holes. The mobility of a charge carrier is represented by the ratio of the velocity of an electron $\left(v_{\mathrm{e}}\right)$ or of a hole $\left(v_{\mathrm{h}}\right)$ to the electric field strength $(E)$ in the semiconductor. Hence, the electron mobility can be represented by $\mu_{\mathrm{e}}=v_{\mathrm{e}} / E$ and hole mobility by $\mu_{\mathrm{h}}=v_{\mathrm{h}} / E$.

In that way, mobility indicates the distance the electron or the hole covers per second in a field of strength $E=1 \mathrm{~V} / \mathrm{cm}$.

Considering the aforementioned, expressions for the electron and the hole current components may be written as [26]

$$
\begin{aligned}
& I_{\mathrm{e}}=N_{\mathrm{e}} \mathrm{e} v_{\mathrm{e}}=N_{\mathrm{e}} \mathrm{e} \mu_{\mathrm{e}} E, \\
& I_{\mathrm{h}}=N_{\mathrm{h}} \mathrm{e} v_{\mathrm{h}},=N_{\mathrm{h}} \mathrm{e} \mu_{\mathrm{e}} E,
\end{aligned}
$$

where $\mathrm{e}$ is the charge of electron or hole and $E$ is the electric field strength.

The conduction current in a semiconductor is

$$
I=I_{\mathrm{e}}+I_{\mathrm{h}}=N_{\mathrm{e}} \mathrm{e} s v_{\mathrm{e}}+N_{\mathrm{h}} \mathrm{e} v_{\mathrm{h}}=N_{\mathrm{e}} \mathrm{e} \mu_{\mathrm{e}} E+N_{\mathrm{h}} \mathrm{e} \mu_{\mathrm{h}} E .
$$

With intrinsic conduction, concentration of electrons is equal to that of holes in semiconductor, that is,

$$
\begin{gathered}
N_{\mathrm{e}}=N_{\mathrm{h}}=N, \\
I=N_{\mathrm{e}}\left(\mu_{\mathrm{e}}+\mu_{\mathrm{h}}\right) E .
\end{gathered}
$$

In a pure (intrinsic) semiconductor impurities constitute not more than $10^{-11} \%$. The investigated natural Umm-Gheig sintered ore containing the iron atoms as impurities of a valency higher than the semiconductor's material tends to give electrons thereby increasing the electron density. They play the role of donors. Thus, the atoms of iron impurities present originally in the native ore can modify its electrical properties. For example, to obtain a semiconductor that will exhibit $\mathrm{n}$-type conduction. This leads to the formation of some $\mathrm{Fe}^{2+}$ ions from $\mathrm{Fe}^{3+}$ ions. The polarization of the ferrite is determined by local displacement [23] of electrons in the direction of an applied electric field, which is due to the electron exchange interaction

$$
\mathrm{Fe}^{2+} \rightleftharpoons \mathrm{Fe}^{3+}+\mathrm{e}^{-}
$$

The energy gap $\left(E_{\mathrm{g}}\right)$ which is defined as the energy required for separating the highest-filled or valence band (V.B) from the conduction band (C.B) is equal to twice [27] the activation energy value, that is, $E_{\mathrm{g}}=2 E_{\mathrm{a}}$.

The values of $E_{\mathrm{a}}$ and $E_{\mathrm{g}}$ for the investigated semiconductor sintered ore samples are calculated and given in Table 3 as follows.
TABLE 3: The effect of sintering temperature $\left(T_{\mathrm{s}}\right)$ on $E_{\mathrm{a}}$ and $E_{\mathrm{g}}$ values.

\begin{tabular}{lcc}
\hline $\begin{array}{l}\text { Sintering } \\
\text { temperature }(\mathrm{K})\end{array}$ & $\begin{array}{c}\text { Activation energy } \\
E_{\mathrm{a}}(\mathrm{eV})\end{array}$ & $\begin{array}{c}\text { Energy gap } \\
E_{\mathrm{g}}(\mathrm{eV})\end{array}$ \\
\hline 573 & 0.850 & 1.70 \\
773 & 0.825 & 1.65 \\
973 & 0.760 & 1.52 \\
1273 & 0.580 & 1.16 \\
\hline
\end{tabular}

3.7. Temperature Dependence of Thermal Conductivity (K). The coefficient of thermal conductivity of the sintered ore samples was estimated using the formula

$$
Q=\frac{I V}{J}=\frac{K A d T}{d X}
$$

where $Q$ is the quantity of heat per unit time transferred through the sample of thickness $d X$ and $J$ is the Joule's coefficient. The parameters $I, U, d T / d X$, and $A$ are the current (in amperes), voltage across the heater (in volts), temperature gradient in (degree/m), and sample area (in $\mathrm{m}^{2}$ ), respectively.

The heat transport through lattice vibrations (phonons) is mainly important for insulators and semiconductors. The thermal conductivity of the sintered ore sample crystals has contributions from two components [28], lattice vibration (phonons) and the carriers (electrons)

$$
K=K_{\text {ph }}+K_{\mathrm{e}} \text {. }
$$

If we consider the heat conduction by electron carriers due to the presence of $\mathrm{Fe}^{2+}$ and $\mathrm{Fe}^{3+}$ impurities, the temperature gradient will cause a carrier concentration gradient, which results in a diffusion current which transports heat energy. At temperatures lower than the Debye temperature, the inelastic scattering processes become important, thus strongly affecting the thermal conductivity. In this range there is a sharp drop in phonon concentration with rising temperatures leading to a sharp increase in $K$, which becomes proportional to $T^{3}$. But at temperatures higher than the Debye temperature, the scattering processes must be responsible for the thermal resistance and the elastic scattering is dominant since the phonon contribution to the thermal conductivity is relatively small compared with the electron contribution.

The measured thermal conductivity is approximately equal to the contribution from electrons. In this range $K$ is inversely proportional to the temperature $\left(K \equiv T^{-1}\right)$.

The temperature dependence of $K$ for the investigated sintered ore samples is shown in Figure 11. A sharp rising of thermal conductivity with rising temperature can be observed up to the transition temperature. The concentration of phonons decreases with rising temperature leading to a consequent decrease in lattice vibrations. This decrease of lattice vibration diminishes lattice scattering causing an increase in the mean free path which would result in an increase in $K$.

Thus, the thermal conductivity $(K)$ increases at low temperature due to the increase of modes of vibration of the 


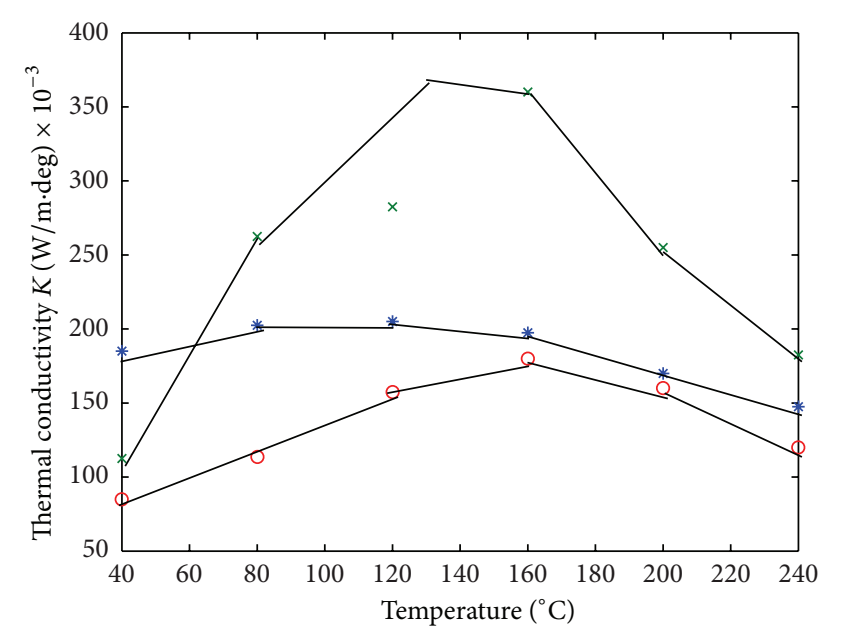

$\circ 573 \mathrm{~K}$
$* 773 \mathrm{~K}$
$\times \quad 973 \mathrm{~K}$

FIgURE 11: Temperature dependence on thermal conductivity $(K)$ for sintered ore samples.

crystal lattice and is responsible for conduction of phonons up to the Debye temperature. Above the transition temperature, or Debye temperature, the concentration of phonons increases with rising temperature leading to lattice scattering causing a decrease in the mean free path which would result in a decrease of $K$. As shown in Figure 11, the values of thermal conductivity $(K)$ increase as the sintering temperature of the tested sintered ore samples is also increased. As the sintering temperature increases the material becomes more dense and the pores decrease. The pores act as scattering centers of phonons, so the decreasing of pores causes the observed increasing of the thermal conduction $(K)$. The maximum values of thermal conductivity of the tested ore samples sintered at 573, 773, and $973 \mathrm{~K}$ were as follows: 180, 210 , and $390 \mathrm{~K}(\mathrm{~W} / \mathrm{m} \cdot \mathrm{deg}) \times 10^{-3}$, respectively, as shown in Figure 11. The results obtained from thermal conductivity $(K)$ measurements are in a good agreement with those obtained from the previous electrical conductivity $(\sigma)$ studies.

The thermoelectric power coefficient $(\alpha)$ was measured experimentally for the investigated sintered ore samples as a function of temperature. The $\alpha$ measured had negative values, demonstrating that the main charge carriers are electrons hopping between $\mathrm{Fe}^{2+}$ and $\mathrm{Fe}^{3+}$ ions which were originally present in the material as impurities (called dopants). Dopant or doping $\mathrm{Fe}$ whose atoms tend to give electrons to the semiconductor, thereby increasing the electron density, is called donor. Iron impurities modify the electrical and thermal properties to obtain a semiconductor that will exhibit $\mathrm{n}$-type conduction. It is clear that the electrons constituting the iron impurity conduction are the chief charge carriers in the investigated semiconductor sintered ore material.

Finally, the conduction current in the investigated semiconductor sintered ore samples is the sum of electronic and hole currents, but electronic current is ten times that of hole current.

Efficient solar conversion requires materials with band gaps [29] of $1.3 \pm 0.3 \mathrm{eV}$, that is, absorption of light in the spectral range of $250-1000 \mathrm{~nm}$. Considerable attention has been given in recent years to the application $[30,31]$ of semiconductor colloids, powders, and films for conversion of solar energy into electricity and chemical energy. The concentration of current carriers and hence semiconductivity increases with increasing temperature according to the Boltzmann distribution [24]. Thus, the obtained experimental energy gap values $\left(E_{\mathrm{g}}\right)$ of the sintered ore samples under consideration, as shown in Table 3 , are suitable and optimum for using the tested natural sintered ore material as a highly absorbing semiconductor in photoelectrochemical systems and thermotechnological applications, as suggested by the following techniques:

(1) nitrogen reduction to ammonia by photosensitized [32] electron transfer from dispersed ore oxides $\left(\mathrm{Fe}_{2} \mathrm{O}_{3}, \mathrm{PbO}_{2}, \mathrm{ZnO}\right)$ doped $\mathrm{TiO}_{2}$ semiconductor particles;

(2) semiconductors in water [33] treatment;

(3) colloidal semiconductors in photovoltaic [27, 34] systems. As known from the Schottky barrier theory, the low bias potential region might be controlled by recombination and trapping of electrons in the depletion region [35]. These processes occur most effectively in localized states energetically centered in the midgap position leading to a recombination current proportional to $[\exp (q V / 2 k T)-1][36,37]$;

(4) it is often necessary that semiconductor materials are exclusively of $n$ - or p-type for many industrial applications, for example, for semiconductor-based rectifiers to rectify alternating current into pulsating direct current. Thus, a system of two semiconductors with different types of electric conduction resists reverse current flow. This property is highly valued for semiconductor rectifiers. Fusing together the two types forms a $\mathrm{p}-\mathrm{n}$ junction that has the property of rectifying alternating current. If we apply an AC voltage to such a system of two semiconductors, the p$\mathrm{n}$ junction will pass the current of only one half cycle of voltage. In crystal diodes, the p-n junction is used chiefly for rectifiers applications;

(5) thermoelectric generation is essentially the same as the energy conversion and heat pumping (when a semiconductor material is used thermoelectrically as a heat pump) with $\mathrm{p}$-type and $\mathrm{n}$-type materials;

(6) partial illumination of a semiconductor induces a photo emf between the illuminated and unilluminated areas of the material surface. This phenomenon is used for making sources of electric power, such as photovoltaic cells and solar batteries and semiconductor devices capable of solar-to-electric energy conversion. 


\section{Conclusions}

The obtained results of electron microscopic investigation for either the native ore or the ore after sintering treatment confirmed by metal value data given in the A.S.T.M. cards coincide well with those given by chemical analysis.

From the observations of $I-V$ characteristics, in $\sigma$ versus $1 / T$ and $K$ versus $T$ behaviours of the investigated natural sintered ore samples, we can summarize the following conclusions.

(1) The sintered ore material had good semiconductivity behaviour with increasing temperature.

(2) The semiconductor sintered ore exhibits n-type conduction.

(3) Both values of $E_{\mathrm{a}}$ and $E_{\mathrm{g}}$ in $\mathrm{eV}$ decrease with increasing the applied sintering temperatures from 573 to $1273 \mathrm{~K}$. Consequently, the electrical conductivity $(\sigma)$ increases in the same range of the studied sintering temperatures.

(4) The thermal phonon scattering and lattice vibration scattering are responsible for the thermal conductivity $(K)$ and the behaviour of the material at changing temperatures.

(5) The above measurements, from electrical, thermal, and semiconductivity behavior of the investigated material, obtained by solid state sintering, may have thermotechnological industrial applications.

\section{Conflict of Interests}

The author declares that there is no conflict of interests regarding the publication of this paper.

\section{References}

[1] A. H. Sabet, V. B. Tsogoev, V. P. Bordonosov, V. A. Beloshitsky, D. N. Kuznetsove, and H. A. El-Hakim, Annals of the Geological Survey of Egypt According to Contract. VI, 1976.

[2] A. M. Eid and M. M. Abd El-Rehime, Metallurgical Research on $\mathrm{Zn}$-Pb Oxidised Ore of Umm-Gheig Deposit, Eastern Desert Geological Survey and Mineral Research Department, Egypt, 1963.

[3] P. V. Viswanathan, B. V. S. Yedavalli, S. R. Srinivasan, and P. P. Bhatnagar, Symposium on Recent Development in Non-Ferrous Metals Technology. Volume 2: Copper, 1968.

[4] H. H. Kellogg, "A critical review of sulfation equilibria," Transactions of the AIME, vol. 230, pp. 1622-1634, 1964.

[5] G. R. Smithson Jr. and J. E. Hanway Jr, "Bench scale development of a sulfation process for complex sulphide ores," Transactions of the Metallurgical Society of AIME, vol. 224, p. 827, 1962.

[6] F. Taha, S. E. Afifi, and L. H. Madkour, "Treatment of UmmSamiuki Complex," Tabbin Institute for Metallurgical Studies, no. 47, pp. 1-19, 1982.

[7] A. P. Snernikar and V. M. Yurenko, "Laboratory studies on the hydrometailurigical treatment of $\mathrm{Cu}-\mathrm{Pb}-\mathrm{Zn}$ intermediate products," Russian Journal of Non-Ferrous Metals, vol. 11, p. 77, 1965.
[8] L. H. Madkour, "Thermodynamic studies on sulphate roasting for zinc electrowinning from carbonate ore," Journal of Chemical Technology and Biotechnology, vol. 36, no. 5, pp. 197-211, 1986.

[9] M. Tao, B. Ai, O. Dorlanne, and A. Loubiere, "Different "single grain junctions" within a $\mathrm{ZnO}$ varistor," Journal of Applied Physics, vol. 61, no. 4, pp. 1562-1567, 1987.

[10] E. Olsson and G. L. Dunlop, "Characterization of individual interfacial barriers in a $\mathrm{ZnO}$ varistor material," Journal of Applied Physics, vol. 66, no. 8, pp. 3666-3675, 1989.

[11] Z. Feng and C. Zechun, "Study on the electrical properties of single grain boundaries in $\mathrm{BaTiO}_{3}$ ceramics," Journal of Applied Physics, vol. 80, no. 2, pp. 1033-1036, 1996.

[12] V. Parvanova, I. Iliev, and L. Ilkov, "Synthesis and microwave properties of doped zinc titanate," Journal of the University of Chemical Technology and Metallurgy, vol. 41, no. 4, pp. 461-466, 2006.

[13] B. Boyanov, "Synthesis and determination of Curie temperature of ferrites from the systems $\mathrm{BaO}-\mathrm{CoO}-\mathrm{ZrO}_{2}-\mathrm{Fe}_{2} \mathrm{O}_{3}$ and $\mathrm{BaO}$ $\mathrm{NiO}-\mathrm{ZrO}_{2}-\mathrm{Fe}_{2} \mathrm{O}_{3}$," Journal of the University of Chemical Technology and Metallurgy, vol. 41, no. 1, pp. 61-64, 2006.

[14] E. Merck, Complexometric Assay Methods with Titriplex, Merck, Darmstadt, Germany, 3rd edition, 1971.

[15] A. A. G. Awad and M. A. Ahmed, "Electrical conductivity in Cuferrites," Proceedings of the Mathematical and Physical Society of Egypt, vol. 42, p. 93, 1976.

[16] D. N. Todor, Thermal Analysis of Minerals, Abacus Press, Tunbridge Wells, UK, 1976.

[17] L. H. Madkour, "Recommended flowsheets for the electrolytic extraction of lead and zinc from red sea polymetal ore," Journal of Chemical Technology and Biotechnology, vol. 35, no. 3, pp. 108114, 1985.

[18] L. H. Madkour, M. M. Abou-Sekkina, and O. M. Hemeda, "Thermo-physical studies on ilmenite ore for mass production of ceramic capacitors," Erzmetall, vol. 49, no. 5, pp. 309-313, 1996.

[19] L. J. Bellamy, The Infrared Spectra of Complex Molecules, Chapman \& Hall, London, UK, 3rd edition, 1975.

[20] K. Nakamoto, Infrared Spectra of Inorganic and Coordination Compounds, John Wiley \& Sons, New York, NY, USA, 1970.

[21] P. J. Jorgensen, Sintering and Related Phenomena, edited by G. G. Kuczynski, N. A. Hooton and C. F. Gibbon, Gordan \& Breach, New York, NY, USA, 1967.

[22] H. Schmalzried, Solid State Reactions, Verlag Chemie, GmbH., Weinheim/Bergstr. and Academic Press, New York, NY, USA, 1974.

[23] B. K. Kuanr and G. P. Srivastava, "Dispersion observed in electrical properties of titanium-substituted lithium ferrites," Journal of Applied Physics, vol. 75, no. 10, pp. 6115-6117, 1994.

[24] J. O. Williams, "Electrical conduction in organic solids," Advances in Physical Organic Chemistry, vol. 16, pp. 159-237, 1978.

[25] D. W. Strickler and W. G. Carlson, "Electrical conductivity in the $\mathrm{ZrO}_{2}$-rich region of several $\mathrm{M}_{2} \mathrm{O}_{3}-\mathrm{ZrO}_{2}$ systems," Journal of the American Ceramic Society, vol. 48, no. 6, pp. 286-289, 1965.

[26] N. Nikulin, Fundamentals of Electrical Materials, Mir Publishers, Moscow, Russia, 1988.

[27] K. Büker, N. Alonso-Vante, and H. Tributsch, "Photovoltaic output limitation of $\mathrm{n}-\mathrm{FeS}_{2}$ (pyrite) Schottky barriers: a temperature-dependent characterization," Journal of Applied Physics, vol. 72, no. 12, pp. 5721-5728, 1992. 
[28] J. S. Blakmore, Solid State Physics, Mir Publisher, Moscow, Russia, 2nd edition, 1988.

[29] R. Memming, "Solar energy conversion by photoelectrochemical processes," Electrochimica Acta, vol. 25, no. 1, pp. 77-88, 1980.

[30] M. Grätzel, Heterogeneous Photochemical Electron Transfer, chapter 3, CRC Press, Boca Raton, Fla, USA, 1989.

[31] P. V. Kamat, Kinetics and Catalysis in Microheterogeneous Systems, edited by M. Grätzel and K. Kalyanasundaram, Marcel Dekker, New York, NY, USA, 1991.

[32] P. P. Radford and C. G. Francis, "Photoreduction of nitrogen by metal doped titanium dioxide powders: a novel use for metal vapour techniques," Journal of the Chemical Society, Chemical Communications, no. 24, pp. 1520-1521, 1983.

[33] M. Grätzel, Aspects of Electrochemistry, edited by R. E. White, J. O. M. Bockris and B. E. Conway, Plenum Press, New York, NY, USA, 1983.

[34] P. Bogdanoff and N. J. Alonso-Vante, "A kinetic approach of competitive photoelectrooxidation of $\mathrm{HCOOH}$ and $\mathrm{H}_{2} \mathrm{O}$ on $\mathrm{TiO}_{2}$ anatase thin layers via on-line mass detection," Journal of Electroanalytical Chemistry, vol. 379, no. 1-2, pp. 415-421, 1994.

[35] E. H. Rhoderick and R. H. Williams, Metal-Semiconductor Contacts, Clarendon Press, Oxford, UK, 2nd edition, 1988.

[36] W. Shockley and W. T. Read, "Statistics of the recombinations of holes and electrons," Physical Review, vol. 87, no. 5, pp. 835-842, 1952.

[37] A. S. Grove, Physics and Technology of Semiconductors Devices, John Wiley \& Sons, New York, NY, USA, 1967. 

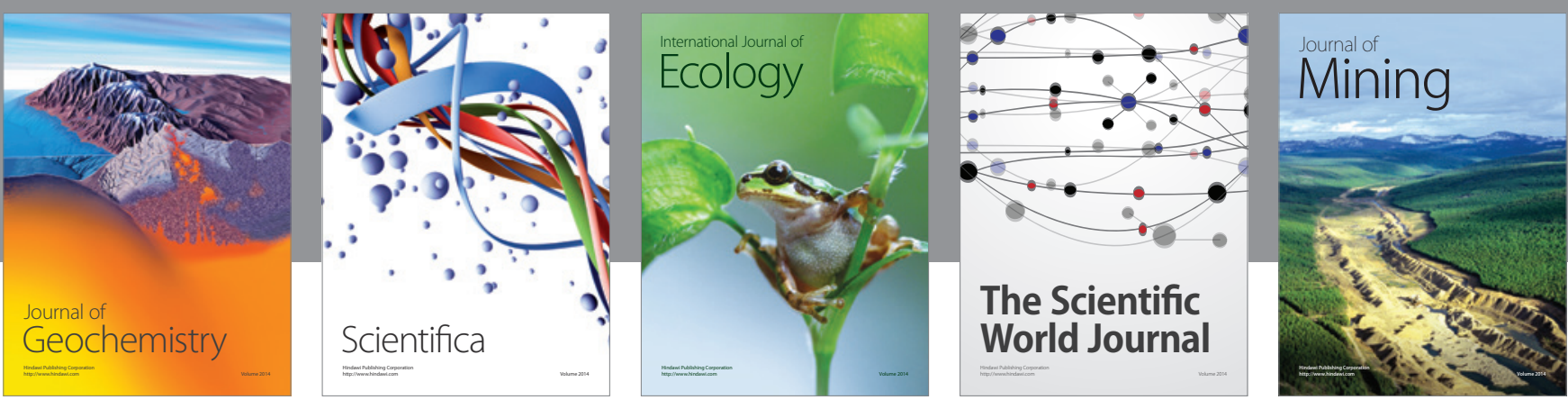

The Scientific World Journal
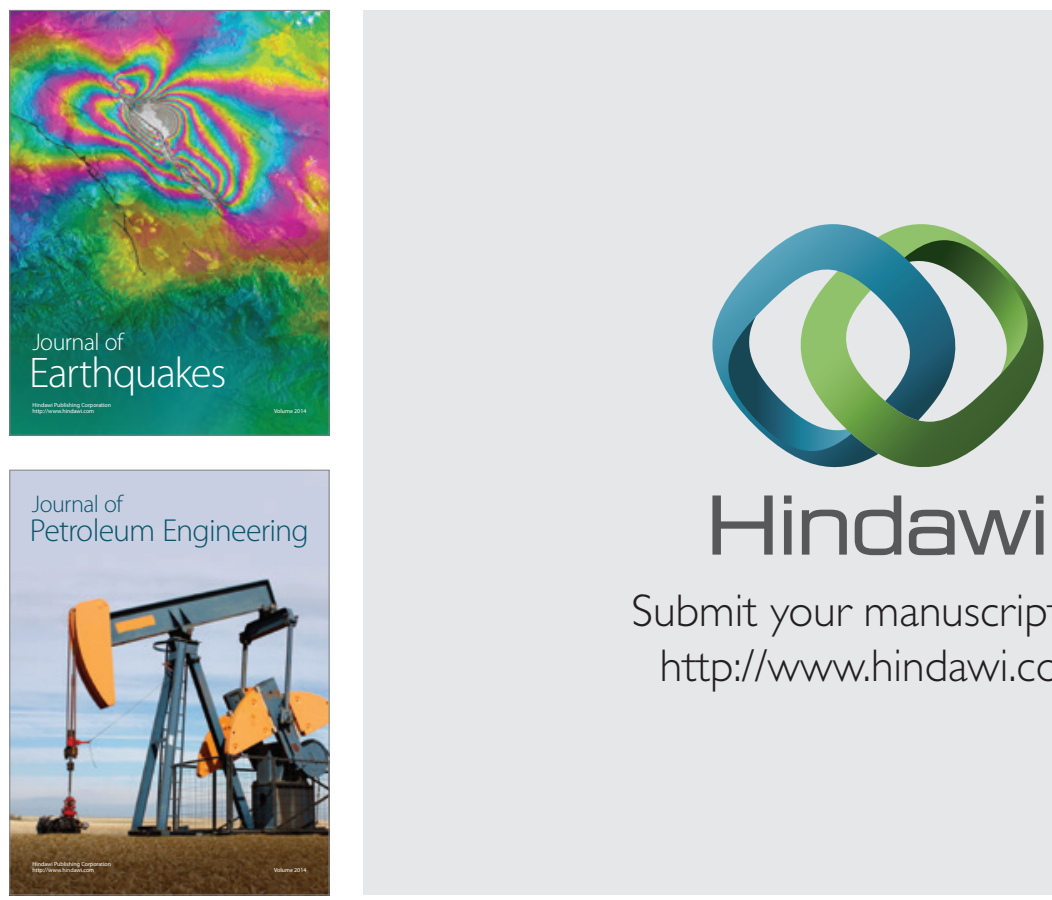

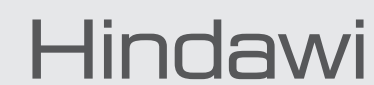

Submit your manuscripts at

http://www.hindawi.com
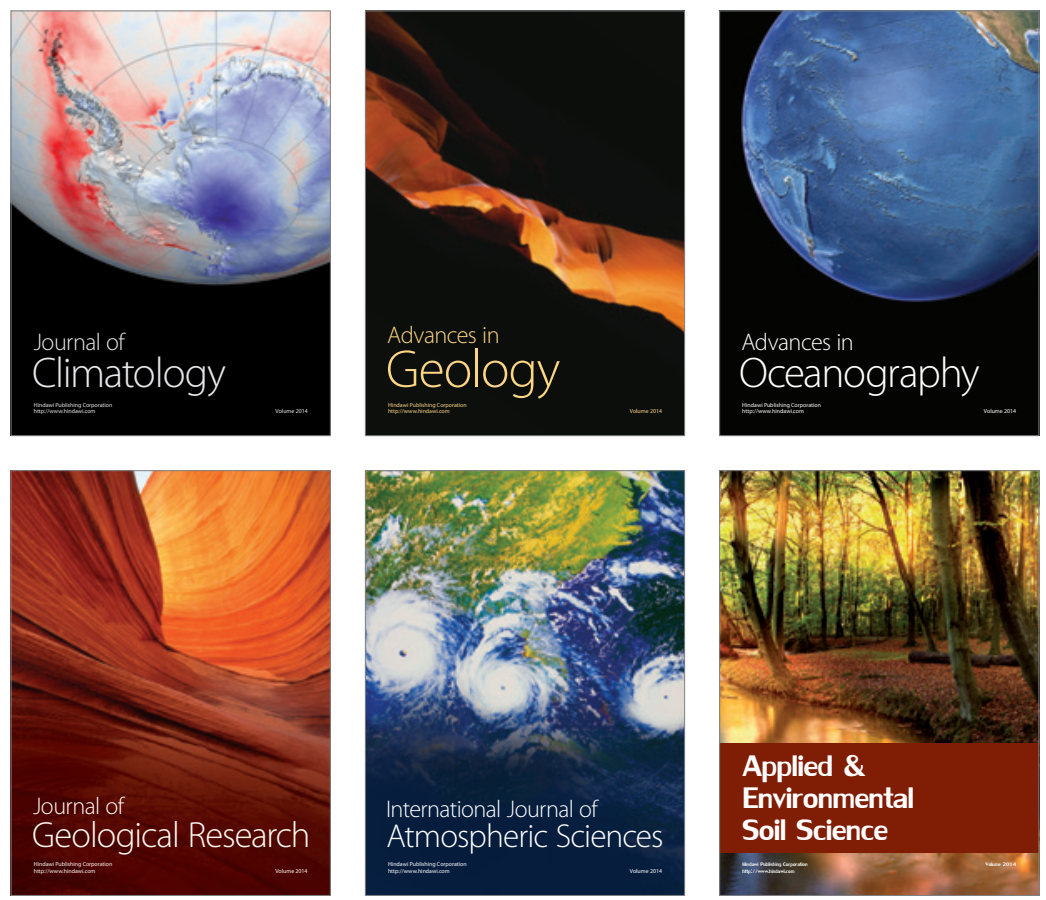
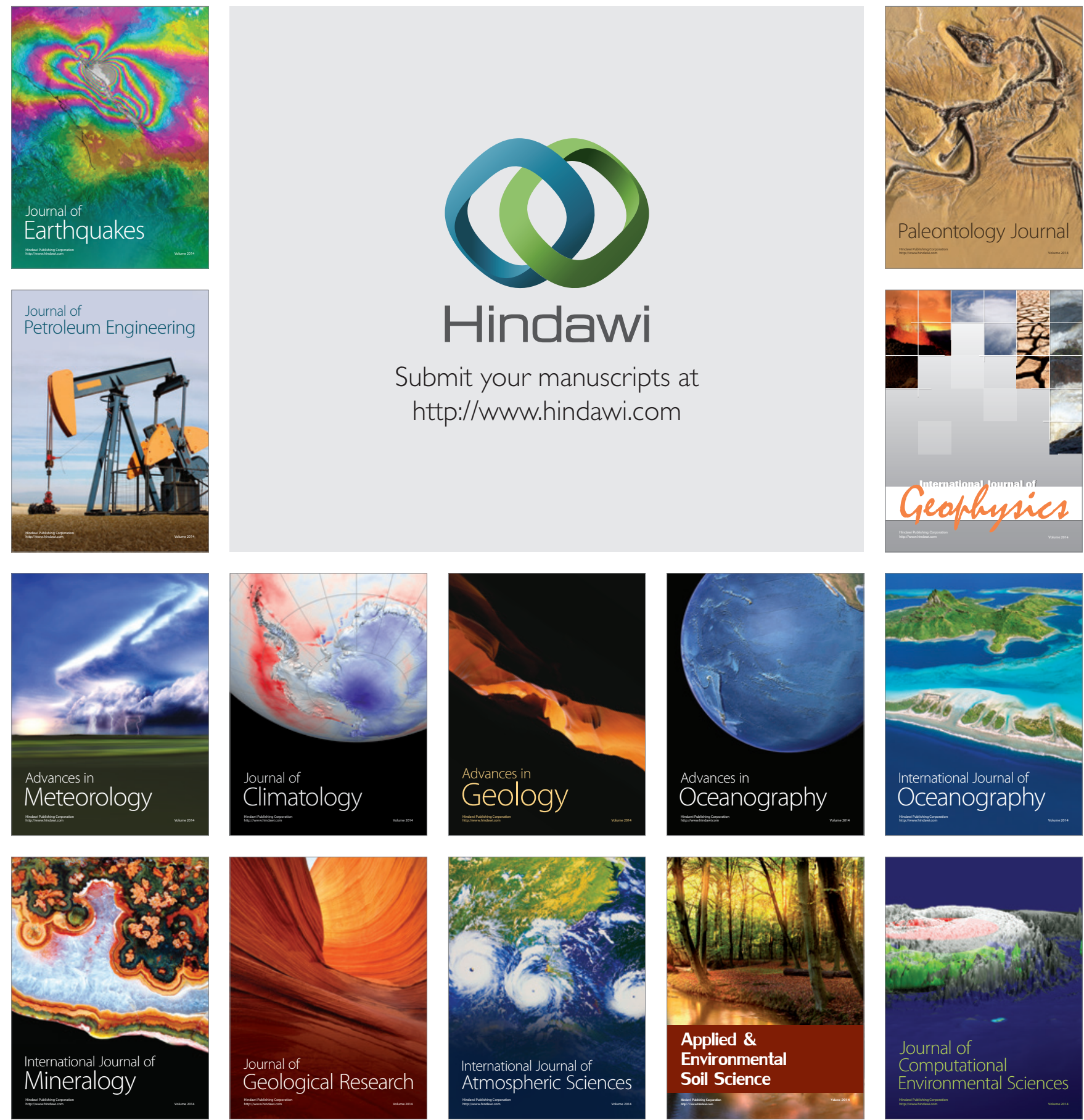